\title{
EKONOMI POLITIK DALAM PENGELOLAAN HUTAN DESA KENEGERIAN GUNUNG SAHILAN
}

\author{
Mayarni dan Dedi Kusuma Habibie \\ FISIP Universitas Riau, Kampus Bina Widya Km. 12,5 Simpang Baru Panam, Pekanbaru 28293
}

\begin{abstract}
Village forest management is part of the social forestry program, in general the program's objectives are economic equality and reducing economic inequality through three pillars, namely: land, business opportunities and human resources, sustainability aspects in its management also become guidelines in managing forests, forest management policies themselves have pros and cons because there are so many interests that pull each other between economic interests and interests to preserve the environment, as well as the management of the village of Gunung Sahilan Kenegerian village, it needs a special review to describe how the implementation of the management of the village of Mount Sahilan Kenegerian village forest, what exactly is expected by various parties with village forest management policies, what are the issues that are considered important that affect village forest management as well as how the impact of the management of the village forest kenegerian Gunung sahilan for the welfare of the community and society environment.
\end{abstract}

\begin{abstract}
Abstrak: Pengelolaan hutan desa merupakan bagian program perhutanan sosial, secara umum tujuan program tersebut adalah pemerataan ekonomi dan mengurangi ketimpangan ekonomi melalui tiga pilar, yaitu: lahan, kesempatan usaha dan sumberdaya manusia, aspek kelestarian dalam pengelolaannya juga menjadi pedoman dalam mengelola hutan, kebijakan pengelolaan hutan sendiri memiliki pro dan kontra karena begitu banyaknya kepentingan yang saling tarik menarik antara kepentingan ekonomi dan kepentingan untuk menjaga kelestarian lingkungan, begitupun dengan pengelolaan hutan desa kenegerian gunung sahilan, perlu tinjaun khusus untuk menggambarkan bagaimana pelaksanaan pengelolaan hutan desa kenegerian gunung sahilan, apa sebenarnya yang diharapkan oleh berbagai pihak dengan kebijakan pengelolaan hutan desa, apa saja isu-isu yang dianggap penting yang mempengaruhi pengelolaan hutan desa serta bagaimana dampak kebijakan pengelolaan hutan desa kenegerian gunung sahilan bagi kesejahteraan masyarakat dan lingkungan.
\end{abstract}

Kata Kunci: ekonomi politik, hutan desa, pengelolaan

\section{PENDAHULUAN}

Hutan desa yang ada di Provinsi Riau berjumlah 22 dengan luas mencapai 53.120 hektar dengan fungsi kawasan Hutan Produksi (HP)/Hutan Produksi Terbatas (HPT) seluas 45.844 hektar dan Hutan Produksi Konversi (HPK) 894 hektar serta Hutan Lindung (HL) seluas 6.382 hektar. Sebagai salah satu hutan desa yang memiliki kawasan hutan terluas, yakni 2.942 hektar, hutan desa Kenegerian Gunung Sahilan menjadi menarik untuk dibahas terkait dengan bagaimana sebenarnya kebijakan pengelolaan hutan berjalan.

Pelaksanaan program hutan desa sampai saat ini masih belum memberikan dampak signifikan terhadap masyarakat. Tiga pilar yang menjadi fokus program hutan desa, yakni lahan, kesempatan usaha dan sumberdaya manusia. Ketiga pilar tersebut masih belum dapat dirasakan oleh masyarakat sekitar hutan desa secara penuh. Pertama, terkait dengan pemanfaatan lahan 2.942 ha belum dapat dimanfaatkan secara maksimal dikarenakan akses yang jauh yang pada akhirnya mengakibatkan pemanafaatan hasil hutan yang belum optimal. Di sisi lain perdebatan terkait dengan pemanfaatan lahan antara masyarakat dan pengelolaan hutan desa sampai saat ini masih dalam proses perundingan.

Kedua, kesempatan usaha yang menjadi salah satu tujuan program hutan desa juga belum dapat dirasakan oleh masyarakat disekitar hutan. Hal ini dikarenakan masyarakat di sekitar hutan pada umumnya bermata pencaharian sebagai nelayan dan petani sawit. Hal ini tentunya memerlukan sosialisasi yang interns oleh pengelola hutan desa kepada masyarakat sekitar hutan untuk mewujudkan partisipasi secara aktif dalam mengelola berbagai potensi hutan. Termasuk juga memberikan pemahaman 
terhadap prinsip-prinsip keberlanjutan dalam pengelolaan hutan. Ketiga, sumber daya manusia yang terlibat dalam pengelolaan dan pemanfaatan hutan sudah cukup baik, namun perlu koordinasi dan sinergi yang baik dalam mengelola hutan desa antara pengelola dan masyarakat di sekitar hutan desa.

Dari isu yang disampaikan di atas, peneliti tertarik untuk menganalisa: (1) bagaimana pelaksanaan pengelolaan hutan desa, khususnya di hutan desa kenegerian Gunung Sahilan, Kabupaten Kampar, Provinsi Riau, (2) bagaimana pihak terkait mengelola hutan desa, (3) apa sebenarnya yang diharapkan oleh berbagai pihak dengan kebijakan pengelolaan hutan desa, (4) apa saja isu-isu yang dianggap penting yang mempengaruhi pengelolaan hutan desa, serta (5) bagaimana dampak kebijakan pengelolaan hutan desa Kenegerian Gunung Sahilan bagi kesejahteraan masyarakat dan lingkungannya.

\section{METODE}

Penelitian ini dilaksanakan di Hutan Desa Kenegerian Gunung Sahilan, Kecamatan Gunung Sahilan, Kabupaten Kampar, Provinsi Riau. Secara geografis dan demografis, kajian ini meliputi setidaknya 6 (enam) desa yang terkena dampak pengelolaan Hutan Desa Kenegerian Gunung Sahilan ini, yaitu Desa Gunung Sahilan, Desa Sahilan Darussalam, Desa Subarak, Desa Makmur Sejahtera, Desa Suka Makmur, dan Desa Sahari. Empat desa terakhir merupakan kawasan lintasan masuk dan keluar dari Hutan Desa Kenegerian Gunung Sahilan. Berdasarkan luasnya, Hutan Desa Kenegerian Gunung Sahilan memiliki luas \pm 2.942 hektar.

Penelitian ini menggunakan metode penelitian kualitatif (Moeleong, 2002; Ndraha, 1997). Untuk menyajikan data agar lebih bermakna dan mudah dipahami, maka dalam penelitian ini teknik analisa data yang dipergunakan adalah deskriptif kualitatif. Disamping melakukan analisis hasil penelitian akan diterjemahkan dan diuraikan secara kualitatif, sehingga diperoleh hasil yang berupa gambaran mengenai situasi atau peristiwa yang terjadi di lapangan. Berbagai data primer dan sekunder terkait dengan pengelolaan hutan desa Kenegerian Gunung Sahilan menjadi bahan dalam menjelaskan bagaimana ekonomi politik dalam pengelolaannya, dengan cara menggambarkan kondisi eksisting sosial ekonomi kemasyarakatan disekitar hutan desa, dapat menjelaskan bagaimana pengelolaan hutan desa berdampak kepada masyarakat di sekitar hutan.

\section{HASIL DAN PEMBAHASAN \\ Hutan Desa Kenegerian Gunung Sahilan}

Dalam perhutanan sosial membuka kesempatan bagi warga masyarakat di sekitar hutan untuk mengajukan hak pengelolaan area hutan kepada pemerintah. Setelah disetujui, maka masyarakat dapat mengolah dan mengambil manfaat dari hutan dengan cara-cara yang ramah lingkungan. Dengan cara ini maska masyarakat akan mendapatkan insentif berupa dukungan teknis dari pemerintah dalam mengelola perkebunan tanaman dalam area yang mereka ajukan. Hasil panen dari perkebunan ini dapat kemudian dijual oleh masyarakat demi pemenuhan kebutuhan ekonominya sehari-hari. Dengan cara demikian pengelolaan kawasan hutan dapat berjalan dengan baik (Karanth, et al., 2006).

Tujuan dari program ini adalah untuk peningkatan kesejahteraan masyarakat melalui mekanisme pemberdayaan dan tetap berpedoman pada aspek kelestarian hutan. Berdasarkan hal tersebut, maka hal ini menjadi kesempatan yang sangat besar bagi masyarakat sekitar hutan untuk dapat mengelola dan memberadayakan lahan hutan. Berdasarkan Permen LHK Nomor 83 tahun 2016 tujuan dari program ini adalah memberikan pedoman pemberian hak pengelolaan, perizinan, kemitraan dan Hutan Adat di bidang perhutanan sosial. Program ini juga bertujuan untuk menyelesaikan permasalahan tenurial dan keadilan bagi masyarakat setempat dan masyarakat hukum adat yang berada di dalam atau sekitar kawasan hutan dalam rangka kesejahteraan masyarakat dan pelestarian fungsi hutan (Brockington, 2007). Program ini memiliki prinsipprinsip dasar, di antaranya adalah keadilan, keberlanjutan, kapasitas hukum, partisipatif, dan bertanggung gugat. 
Penyelenggaraan hutan desa pada dasarnya bertujuan untuk meningkatkan kesejahteraan masyarakat setempat secara berkelanjutan dan menjamin kelestarian lingkungan. Oleh sbab itu, pelaku utama hutan desa adalah Lembaga Desa yang dalam hal ini lembaga kemasyarakatan yang ditetapkan dengan Peraturan Desa (Perdes) secara fungsional berada dalam organisasi desa dan bertanggung jawab kepada Kepala Desa dan diarahkan menjadi Badan Usaha Milik Desa (BUMDes). Dalam pelaksanaannya, menurut Nayak, and Berkes (2008), program hutan desa diarahkan sesuai prinsip-prinsip berikut: 1) tidak mengubah status dan fungsi kawasan hutan; dan 2) ada keterkaitan masyarakat terhadap sumber daya hutan. Karena hutan mempunyai fungsi sosial, ekonomi, budaya dan ekologis, maka pengelolaan hutan desa selain berorientasi ekonomi juga mempertimbangkan aspek lainnya yang merupakan satu-kesatuan tak terpisahkan misalnya aspek lingkungan.

Selain itu yang perlu diketahui adalah hutan desa itu merupakan hutan negara yang dikelola oleh masyarakat lembaga desa, sehingga untuk menerapkan pengelolaan hutan desa harus berlandaskan aturan hukum negara dan atau kebijakan pemerintah baik pusat maupun daerah. Perlunya memberikan pemahaman terhadap pengelolaan pemanfaatan hasil hutan yang memperhatikan aspek ketersediaan dan keanekaragaman hayati hutan, perlunya peran pemerintah dan pihak terkait secara bersama untuk mengawasi pemanfaatan hasil hutan agar tidak berlebihan (E. J. Luoga, dkk 2005). Oleh karena itu, hutan desa memiliki beberapa kriteria: 1) kawasan hutan desa berada dalam kawasan hutan negara seperti hutan lindung dan hutan produksi, 2) belum dibebani hak pengelolaan atau izin pemanfaatan untuk bentuk pengelolaan lain dan 3) kawasan hutan berada dalam wilayah administrasi desa yang bersangkutan.

Sebagai upaya politik dan administratif penetapan kebijakan hutan desa di kecamatan Gunung Sahilan, maka dapat dideskripsikan mengenai aktor-aktor yang terlibat, siapa mendapat apa untuk menjawab "hutan desa untuk siapa?" Secara umum, jika merujuk pada peraturan yang terkait dengan program perhutan sosial maka akan ditemukan berbagai aktor yakni: a) Lembaga pengelola hutan desa (LPHD)/ lembaga Adat, b) Kelompok Tani, Gabungan Kelompok Tani (Gapoktan), Koperasi, c) Masyarakat Hukum Adat (MHA) dan d) lembaga Masyarakat Desa Hutan (LMDH).

Hutan Desa Kenegerian Gunung Sahilan yang berada di Kecamatan Gunung Sahilan Kabupaten Kampar menjadi salah satu hutan desa yang memperoleh izin kelola hutan di provinsi dari Kementerian Lingkungan Hidup dan Kehutanan Republik Indonesia pada tahun 2017 Nomor SK.3887/Menlhk-PSKL/PKPS/ PSL.0/7/2017 tentang pemberian hak pengelolaan hutan desa kepada Lembaga Pengelola Hutan Desa (LPHD) Kenegerian Gunung Sahilan dengan luas 2.942 hektar yang berada pada kawasan hutan produksi terbatas seluas \pm 2.751 hektar dan pada kawasan hutan produksi tetap seluas \pm 191 hektar.

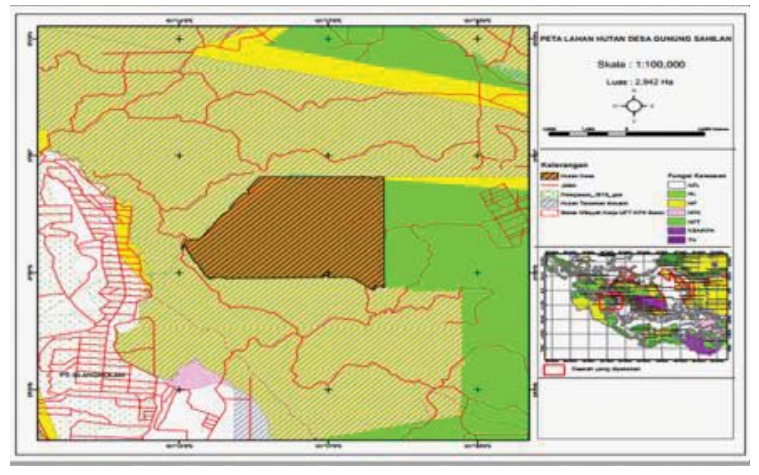

Gambar 1.Peta Kawasan Hutan Desa Kenegerian Gunung Sahilan

Pengurus LPHD Kenegerian Gunung Sahilan terdiri dari unsur-unsur yang diwakili oleh ninik mamak dan juga pihak pemerintahan desa. Hutan Desa Kenegerian Gunung Sahilan ini merupakan hutan desa yang berbasiskan masyarakat adat yang disepakati bersama oleh dua desa, yaitu Desa Gunung Sahilan dan Desa Sahilan Darusalam yang berada di bawah satu tampuk payung Kenegerian Gunung Sahilan. Secara umum telah digambarkan secara singkat bahwa pihak yang terlibat dalam pengelolaan hutan desa di Kecamatan Gunung Sahilan terkonsentrasi pada masyarakat desa dengan 
berbagai perangkat pemerintahan desa maupun perangkat adat, oleh karena itu secara umum pengelolaan hutan desa di Kenegerian Gunung Sahilan telah menjadikan masyarakat setempat sebagai pelaku/pengelola utama hutan desa.

Namun dalam prakteknya ternyata terjadi konflik kepentingan dalam pengelolaan hutan desa Kenegerian Gunung Sahilan terkait dengan pemanfaatan hasil hutan produksi tetap yang terlanjur tanam (Pohon Akasia) seluas \pm 191 Hektar. Adanya perbedaan persepsi kemitraan terhadap perusahaan yang akan dijadikan mitra dalam memanfaatkan hasil hutan tersebut. Kemudian praktek lainnya juga terjadi kendala terkait pemanfaatan hasil hutan, yaitu belum terbentuknya berbagai kelompok petani yang secara khusus melaksanakan pemanfaatan hasil hutan menggambarkan belum siapnya mengelola hasil hutan. Jumlah penduduk desa Gunung Sahilan berjumlah 2413 jiwa dengan jumlah laki-laki 1285 orang dan perempuan 1128 orang. Sedangkan jumlah penduduk desa Sahilan Darussalam berjumlah 1028 terdiri dari laki-laki 518 orang dan perempuan 510 orang. Secara umum, pekerjaan mayoritas masyarakat yang berada di daerah tersebut adalah nelayan, dan sebagian lagi bekerja di bidang perkebunan sawit dan karet. Kondisi demografis ini merepresentasikan bahwa sesungguhnya ada ribuan penduduk desa yang berhak untuk mengambil dan menikmati manfaat secara ekonomis dari keberadaan Hutan Desa Kenegerian Gunung Sahilan.

Kemudian akses yang cukup jauh dari tempat tinggal masyarakat setempat. Jarak yang ditempuh untuk mencapai lokasi hutan desa sekitar $\pm 60 \mathrm{~km}$ dari Desa Sahilan Darusalam dan Desa Gunung Sahilan. Jarak yang cukup jauh ini diakibatkan belum adanya akses yang dekat dari desa menuju hutan desa karena akses satu-satunya melalui jalan peru-sahaan, sehingga tidak semua orang dapat dengan mudah masuk ke hutan desa bahkan anggota LPHD saja tidak diizinkan masuk tanpa izin dari perusahaan. Berbagai catatan tersebut tentu menjadi perhatian bagi pengelola hutan desa khususnya untuk bagaimana secara musyawarah dan mufakat untuk memanfaatkan hasil hutan yang ada sesuai dengan peruntukkannya dengan memperhatikan asas keadilan dan pemerataan bagi masyarakat desa, serta yang terpenting juga harus mampu memperhatikan aspek lingkungan dan keberlanjutan ketika mengelola sumber daya hutan. Hutan desa (secara umum) memiliki beberapa potensi yang cukup tinggi untuk dikembangkan, misalnya menciptakan lapangan kerja baru bagi masyarakat setempat, dengan terciptanaya lapangan kerja tersebut tentu akan berpengaruh juga terhadap meningkatnya pendapatan masyarakat, selain itu akan muncul industri-industri kecil olahan baik itu hasil hutan kaya maupun bukan kayu, ini semua semata-mata bertujuan menciptakan kemandirian untuk desa.

\section{Dinamika Pengelolaan Hutan Desa}

Pemerintah pusat sudah mengupayakan percepatan pembangunan sektor kehutanan berbasis masyarakat, berkelanjutan dan lestari melalui model hutan desa. Oleh karena itu pada tahun 2010 telah diterbitkan peraturan Dirjen Kehutanan tentang Pedoman Indentifikasi dan Inventarisasi Hutan Desa dan Hutan Kemasyarakatan-HKm (Perdirjen RLPS P.01/ 2010). Selain itu juga sudah ada Rencana Indikatif Nasional dimana terdapat potensi pengembangan HKm dan Hutan Desa seluas kurang lebih 1,8 juta Ha. Kontinuitas ekonomi masyarakat lokal dalam bentuk produksi makanan pokok berupa buah, sayur-sayuran, dan tanaman medis selama ini didukung oleh penanaman komoditas hutan. Peran hutan sebagai penyedia jasa layanan ekosistem lengkap dengan biodiversitas yang terkandung di dalamnya diketahui mampu memenuhi citacita perkembangan berkelanjutan bagi populasi dengan tetap mempertahankan kelestarian lingkungan. Berdasarkan riset yang dilakukan WRI (World Resource Institute), produk hutan telah menyumbang sekitar 20 persen nominal pendapatan masyarakat lokal dan menyediakan perlidungan tropis bagi diversitas biologi terestrial, di samping itu, hutan telah lama diakui telah berkontribusi sebagai elemen strategis dalam stabilisasi iklim bumi.

Belajar kondisi pengelolaan hutan les- 
tari di Polandia cukup memuaskan, dengan mempertahankan dan mengintensifkan semua proses dan proyek kegiatan yang ditujukan untuk pengembangan pelaksanaan konsep pembangunan berkelanjutan khususnya pada bidang pengelolaan hutan secara lestari (Bartniczak, 2018). Dengan mendapatkan hak pengelolaan hutan desa, masyarakat yang tinggal di dalam dan di sekitar hutan berpotensi sangat besar dalam meningkatkan kesejahteraan hidupnya. Hal ini dimungkinkan karena pemegang hak pengelolaan hutan desa berhak memanfaatkan kawasan, jasa lingkungan, pemungutan hasil hutan kayu dan bukan kayu. Namun untuk di hutan lindung tidak diijinkan memanfaatkan dan memungut hasil hutan kayu. Dalam memanfaatkan kawasan hutan desa, baik yang berada di hutan lindung maupun hutan produksi masyarakat dapat melakukan berbagai kegiatan usaha, yaitu budidaya tanaman obat, tanaman hias, jamur, lebah, penangkaran satwa liar, atau budidaya pakan ternak.Sedangkan dalam memanfaatkan jasa lingkungan dapat melalui kegiatan usaha pemanfaatan jasa aliran air, pemanfaatan air, wisata alam, perlindungan keanekaragaman hayati, penyelamatan dan perlindungan lingkungan, atau penyerapan dan penyimpanan karbon.

Seperti yang telah dijelaskan sebelumnya bahwa terdapat potensi yang dapat dimanfaatkan secara langsung oleh masyarakat desa yang secara ekonomis memiliki nilai jual tinggi namun disisi lain masyarakat juga memiliki tanggung jawab untuk menjaga kelestarian ekosistem lingkungannya. Dalam penelitian Motoshi dkk (2019) menjelaskan bagaimana pemberiaan hak melalui konservasi hutan dan lahan berkontribusi positif terhadap upaya pembangunan berkelanjutan, berbagai kegiatan pemanfaatan lahan seperti membangun perkebunan karet yang dikelola dengan baik memberikan peluang mata pencaharian baru. Hasil dari survei sosial-ekonomi menunjukkan bahwa kegiatan kelompok dan kerja sama di antara para pemangku kepentingan sangat penting untuk meningkatkan mata pencaharian dan praktik pengelolaan hutan.

Pemberian hak pengelolaan hutan kepada lembaga pengelola hutan desa dapat menimbul- kan dilematika yang cukup berarti manakala di tingkat akar rumput belum terbangun pemahaman yang sama terkait pentingnya hutan bagi masyarakat. Sampai disini dapat dikatakan bahwa hutan desa menimbulkan paradoks yang harus dicermati oleh seluruh pihak terkait. Pertama, secara fungsional, hutan desa sangat potensial untuk mendukung kelestarian hutan. Hal ini akan terjadi apabila masyarakat yang diberikan izin memahami bahwa hutan adalah bagian dari kehidupan masyarakat, artinya praktek perlindungan, pemanfaatan hutan adalah bagian dari tradisi masyarakat yang tidak terpisahkan, Kedua, hutan desa juga memiliki potensi merusak kelestarian hutan tatkala pemberian izin pengolaan hutan akan memberikan manfaat secara ekonomis membuka berbagai peluang usaha. Namun yang menjadi kekhawatiran adalah, aspek ekonomi lebih utama dari aspek kelestaraian hutan, pengelolaan hasil hutan dan pemanfaatannya hanya memfokuskan kepada aspek ekonomi (mencari keuntungan), secara jangka panjang tentu hal ini akan berdampak pada keanekaragaman hayati hutan sehingga tidak menutup kemungkinan ekosistem hutan akan berubah.

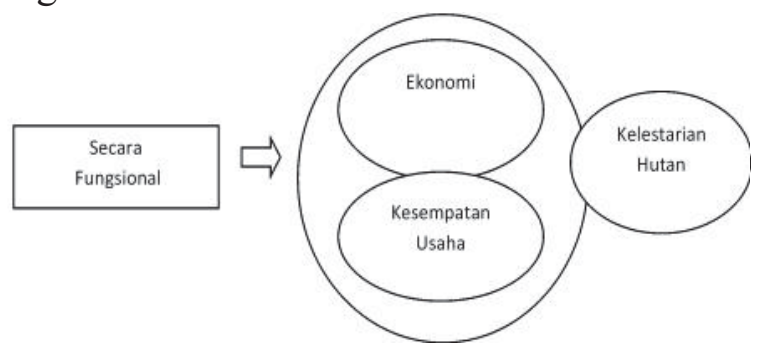

Gambar 2. Dinamika Pengelolaan Hutan Desa

Terdapat nilai kearifan lokal yang ada di Kenegerian Gunung Sahilan yang masih dijaga sampai saat ini yaitu a) dalam urusan pemerintahan maka yang dikedepankan adalah kepala desa, b) dalam urusan keagamaan yang dikedepankan adalah ulama, c) dalam urusan hutan sungai dan tanah ulayat yang dikedepankan adalah ninik mamak. Kusumasari, and Alam, (2012), kearifan lokal tersebut memiliki aspek kolektif dalam mengelola kegiatan masyarakat desa, pembagian yang jelas diantara para pihak dapat menjelaskan siapa mengerjakan apa, dan tanggung jawabnya. 
Hutan desa Kenegerian Gunung Sahilan merupakan bekas zona pemanfaatan kawasan Hak Pengusahaan Hutan (HPH) oleh PT. Hutani Sola Lestari (HSL) yang menyimpan begitu banyak potensi dan mampu mendatangkan banyak nilai ekonomi bagi masyarakat sekitar hutan desa. Walaupun kondisi hutan bukan lagi hutan primer (Pornpimon, Wallapha, and Prayuth, 2014). Tetapi pada kenyataanya LPHD dan masyarakat belum dapat memanfaatkan dan berdampak kepada ekonomi masyarakat, walaupun Rencana Pengelolaan Hutan Desa jangka panjang (35 tahun), rencana jangka menengah (10 tahun) dan rencana jangka pendek (1 tahun) telah disusun. Dimana belum adanya kegiatan pengelolaan hutan akan berimplikasi pada belum adanya manfaat yang dirasakan oleh masyarakat secara maksimal. Dalam jangka panjang akan berdampak pada kinerja dari program hutan desa tersebut. Ketika hak pengelolaan diberikan namun belum memiliki kebermanfaatan maka masyarakat tidak lagi memiliki perhatian terhadap kegiatan pengelolaan hutan tersebut (Dahliani, 2015).

Peneliti merangkum setidaknya ada beberapa hambatan pengembangan perhutanan diantaranya sebagai berikut: 1) Kurangnya Pemahaman Masyarakat terhadap Perhutanan sosial, sehingga masyarakat yang terlibat aktif dalam program tersebut masih tergolong minim, 2) akses ke lokasi perhutanan sosial yang terpencil dikarenakan sebagian lahan berbatasan langsung dengan hutan lindung yang jauh berada di dalam hutan, 3) Akses masyarakat dalam bidang ekonomi, juga menjadi tantangan program perhutanan sosial untuk mendekatkan masyarakat pada sistem ekonomi, seperti koperasi untuk menampung hasil produksi perhutanan sosial, dan 4) minimnya jumlah pendamping yang dapat mendampingi masyarakat secara intensif.

\section{Antara Kesejahteraan dan Kelestarian Lingkungan}

Hutan desa dapat dimakanai dari berbagai sudut pandang yakni a) teritorial berkaitan dengan wilayah administrasi sebuah desa definitif yang diakui dan ditetapkan oleh kesepakatan bersama masyarakat, b) status berkaitan dengan kawasan hutan negara yang terletak pada wilayah asministraai desa tertentu yang ditetapkan oleh pemerintah sebagai hutan desa c) aspek pengelolaan dimana hutan desa adalah kawasan hutan milik rakyat dan milik pemerintah yang berada dalam satu wilayah administrasi desa yang ditetapkan pengelolaannya secara bersama sama antara pemerintah daerah dan pemerintah sebagai hutan desa yang dikelola oleh masyarakat desa (Awang, 2003). Dalam penelitian yang dilakukan oleh Gökçe Gençay dkk (2018) menjelaskan perlunya mensinergikan berbagai kebijakan tentang pengelolaan hutan yang harus memperhatikan fungsi lahan, tidak dapat dipungkiri bahwa kebutuhan penduduk semakin kompleks dan terkadang akan berhadapan pada perubahan fungsi lahan sebagai kebutuhan ekonomi atau kebutuhan lingkungan.

Penetapan kawasan Hutan Desa, idealnya melalui fasilitasi oleh Kementerian Kehutanan, Bupati, Dinas Provinsi, Dinas Kabupaten, UPT (BPDAS/ BPKH/BP2HP), LSM, PT dsb. Adapun prosesnya yakni: 1) Penentuan calon Hutan Desa berdasar hasil identifikasi dan iventariasasi atau usulan kepala desa; 2) Pengusulan areal kerja Hutan Desa oleh Bupati kepada Menteri Kehutanan atas usulan kepala desa; 3) Verifikasi oleh Tim dari pemerintah pusat (kementerian); dan selanjutnya 4) Penetapan areal kerja Hutan Desa oleh Menteri Kehutanan. Sedangkan hal-hal yang harus dilalui dalam prosesnya sesuai ketentuan yang berlaku bahwa Prinsip Perijinan pada Hutan Desa adalah: 1) Penetapan Areal Kerja HKm oleh Menteri Kehutanan; 2) Hak Kelola Hutan Desa diberikan oleh Gubernur kepada Lembaga Desa; 3) Hak Kelola Hutan Desa berlaku selama 35 Tahun dan dapat diperpanjang; 4) Hak Pengelolaan Hutan Desa bukan merupakan hak kepemilikan atas kawasan hutan, tidak mengubah status dan fungsi kawasan hutan serta dilarang memindahtangankan atau mengagunkan; 5) Pemanfaatan Kayu di Hutan Desa dapat dilakukan pada Hutan Desa yang berfungsi sebagai Hutan Produksi melalui Ijin Usaha Pemanfaatan Hasil Hutan Kayu yang 
diberikan oleh Menhut (dapat dilimpahkan kepada Gubernur untuk Hutan Alam, dan Bupati utk Hutan Tanaman).

Menurut Hendriyo dalam Refniza (2018), Sumber daya alam hutan memberikan kontribusi penting dalam pembangunan dan kehidupan masyarakat. Hutan menyediakan kayu, non kayu, hasil hutan dan jasa perlindungan lain, seperti melindungi dari bahaya erosi, longsor ataupun banjir. Hutan juga memiliki manfaat seperti nilai ekonomi,sosial dan perlindungan ekosistem. Berdasarkan dokumen Rencana Kerja Tahun (RKT) Hutan Desa Kenegerian Gunung Sahilan Tahun 2018, terdapat beberapa program dan kegiatan yang telah disusun untuk dilaksanakan pada tahun 2018. Program kegiatan yang dimaksud adalah sebagai berikut: a) Pemanfaatan potensi kawasan, b) Pemanfaatan dan pemungutan hasil hutan kayu, c) Pemanfaatan dan Pemungutan hasil hutan bukan kayu, d) Pembudidayaan pengembangan jenis jenis kayu penting (jenis kayu lokal)., e) Pemanfaatan kawasan hutan, f) Pengembangan jasa lingkungan, g) Pemanfaatan kayu jenis akasia yang terlanjur tumbuh di lokasi hutan desa, dan g) Pengembangan Kelembagaan Hutan Desa Kenegarian Gunung Sahilan.

Memperhatikan berbagai program atau kegiatan tersebut secara umum masih memfokuskan pada aspek ekonomi, apabila memperhatikan Pengelolaan Hutan Lestari (Sustainable Forest Management/SFM) dimana Pengelolaan hutan lestari bertujuan untuk kepentingan sosial, ekonomi dan lingkungan. Tentu program atau kegiatan yang dirumuskan hendaknya memiliki komposisi kegiatan yang proporsional atau seimbang antara kegiatan ekonomi, sosial dan lingkungan. Kriteria Pengolahan Hutan Lestari dapat dilihat sebagai berikut: a) Pengelolaan hutan yang lestari adalah kegiatan eksploitasi yang secara regular untuk mendapatkan sejumlah hasil hutan tanpa adanya pengrusakan atau secara radikal tidak merubah komposisi dan struktur tegakan hutan secara keseluruhan, dan b) Pengelolaan hutan yang lestari ialah terkontrolnya pembalakan hutan yang dikombinasikan dengan praktek silvikultur dengan tujuan mempertahankan atau meningkatkan nilai tegakan secara berturutturut agar terjadi regenerasi alami.

Perhutanan sosial memberi ruang partisipasi masyarakat dalam mengelola hutan bukan memiliki kawasan hutan, perhutanan sosial merupakan suatu harapan jika masyarakat memahami untuk memanfaatkan kawasan dan akan menjadi ancaman jika masyarakat masih berpersepsi penguasaan (memiliki) kawasan. Mayoritas masyarakat di Provinsi Riau tidak memiliki karakter masyarakat petani hutan namun lebih cenderung kepada pemilik lahan.

\section{SIMPULAN}

Tiga pilar, yaitu: lahan, kesempatan usaha dan sumberdaya manusia dalam program Perhutanan Sosial hendaklah menjadi landasan dasar dalam setiap kegiatan pengelolaan hutan desa. Hal ini bertujuan agar manfaat yang dirasakan oleh masyarakat tidak hanya sekedar pada aspek ekonomi semata melainkan lebih penting lagi adalah bagaimana keberlanjutan lingkungan yang dapat menompang kehidupan di sekitar hutan desa melainkan juga di luar dari areal hutan desa. Program hutan desa di Kenegerian Gunung Sahilan merupakan salah satu kebijakan yang memberikan hak pengelolaan hutan desa kepada masyarakat desa melalui pendirian lembaga pengelola hutan desa untuk mengelola hutan seluas \pm 2.751 , dalam melaksanakan berbagai kegiatan pengelolaan hutan hendaknya juga memperhatikan tiga pilar. Hal ini bertujuan agar pengelolaan hutan dapat dirasakan oleh seluruh masyarakat yang ada di daerah kenegerian gunung sahilan khususnya dan masyarakat yang ada di daerah Kabupaten Kampar Riau pada umumnya.

\section{DAFTAR RUJUKAN}

Awang, S.A,. 2003. Hutan Desa: Realitas tidak terbantahkan sebagai alternatif model pengelolaan hutan di Indonesia. Dalam Prosiding Seminar Hutan Desa: Alternatif Pengelolaan Hutan Berbasis Masyarakat. Yayasan DAMAR \& The Ford Foundation. Yogyakarta.Bartosz Bartniczak, Andrzej Raszkowski, (2018) "Sustainable forest management in Poland", 
Management of Environmental Quality: An International Journal, Vol. 29 Issue: 4, pp.666-677, https://doi.org.ezproxy. ugm.ac.id/10.1108/MEQ-11-2017-0141

Brockington, D. (2007). Forests, community conservation, and local government perfomance: The village forest reserves of Tanzania. Society and Natural Resources. https://doi.org/10.1080/ 08941920701460366

Dahliani, D. (2015). Local wisdom in built environment in globalization era. International Journal of Education and Research.

Gençay, G., Birben, Ü., \& Durkaya, B. (2018). Effects of legal regulations on land use change: $2 / \mathrm{B}$ applications in Turkish forest law. Journal of sustainable forestry, 37, 804-819. doi: 10.1080/10549811. 2018.1486717

Higman S. dkk. 2006. The Sustainable Forestry Handbook, Second edition. Earthscan, London.

Hiratsuka, M., Nakama, E., Satriadi, T., Fauzi, H., Aryadi, M., \& Morikawa, Y. (2019). An Approach to Achieve Sustainable Development Goals Through Participatory Land and Forest Conservation: A Case Study in South KALIMANTAN Province, Indonesia. Journal of Sustainable Forestry. https://doi.org/10.1080/ 10549811.2019.1598440

Karanth, K. K., Curran, L. M., \& ReuningScherer, J. D. (2006). Village size and forest disturbance in Bhadra Wildlife Sanctuary, Western Ghats, India. Biological Conservation. https://doi.org/ 10.1016/j.biocon.2005.09.024

Kusumasari, B., \& Alam, Q. (2012). Local wisdom-based disaster recovery model in Indonesia. Disaster Prevention and Management: An International Journal. https://doi.org/10.1108/09653561 211234525
Luoga, E.J.; Kajembe, G.C.; Shemweta, D.T.K.; Zahabu, E.; Mwaipopo, C.S.; Kweka, D.L., Assessment of tree stocking and diversity for Joint Forest Management (JFM) in Nkweshoo village forest management area, Kilimanjaro, Tanzania, Forests, Trees and Livelihoods 15(3): 259-273 2005, https://eurekamag.com/research/004/ 049/004049842.php

Moleong, Lexy. (2002). Metodologi Penelitian Kualitatif. Bandung: PT. remaja Rosdakarya.

Nayak, P. K., \& Berkes, F. (2008). Politics of co-optation: Community forest management versus joint forest management in Orissa, India. Environmental Management. https://doi.org/10.1007/s00267-0089088-4

Ndraha, Taliziduhu, 1997. Metodologi Ilmu Pemerintahan. Jakarta: Rineka Cipta.

Pornpimon, C., Wallapha, A., \& Prayuth, C. (2014). Strategy Challenges the Local Wisdom Applications Sustainability in Schools. Procedia - Social and Behavioral Sciences. https://doi.org/10.1016/ j.sbspro.2014.01.1210

Refniza Yanti, Almasdi Syahza, Achmad Hidir, Suwondo, (2018) "The communication model of forest management based on environmental awareness", Management of Environmental Quality: An International Journal, Vol. 29 Issue: 6, pp.1093-1109, https://doi.org.ezproxy. ugm.ac.id/10.1108/MEQ-02-2018-0028

Samadhi, Nirarta.,2018. Usaha Penurunan Angka Deforestasi dalam Rangka Mendukung Pencapaian Target SDG, Lokakarya hutan dan deforestasi, Jakarta

Sobur, A. (2005). Peliputan Isu Lingkungan dan Pembangunan Berkelanjutan. Mediator, 6(2), 183-190. 